\title{
Osteoporosis in men: its pathophysiology and the role of teriparatide in its treatment
}

\author{
Claudia Gagnon \\ Vivien Li \\ Peter R Ebeling \\ Department of Medicine, University \\ of Melbourne, Melbourne, Australia
}

Correspondence: Peter R Ebeling

Department of Medicine, The University

of Melbourne, Western Hospital, Cnr

Eleanor and Marion Streets, Footscray,

VIC 30II, Australia

Tel +6I 383456429

Fax +6139318 II57

Email peterre@unimelb.edu.au

\begin{abstract}
As the population ages, the burden of osteoporosis in men is expected to rise. Implementation of preventive measures such as falls prevention strategies, exercise and adequate calcium and vitamin D intake is recommended. However, when the diagnosis of osteoporosis is made, effective treatments need to be initiated to prevent fractures. As opposed to postmenopausal women, reduced bone formation is the predominant mechanism of age-related bone loss in men, making anabolic agents a logical treatment option for men with osteoporosis. Teriparatide is the only anabolic agent currently approved for treatment of osteoporosis in men. This paper summarizes the mechanism of action of teriparatide, as well as its tolerability and safety. Furthermore, the evidence supporting the efficacy of teriparatide treatment in men with osteoporosis is reviewed and its current role in the management of osteoporosis in men is discussed.
\end{abstract}

Keywords: osteoporosis, pathophysiology, treatment, parathyroid hormone, men

\section{Osteoporosis in men Scope of the problem}

Although the majority of research on osteoporosis in the past has focused on women, osteoporosis is also becoming an increasingly important problem in men. One in $8 \mathrm{men}$ aged over 50 will have an osteoporosis-related fracture (Cooper and Melton 1992) and this figure is predicted to rise with an aging male population (Burge et al 2007). Although fragility fractures in men occur an average of 10 years later compared with those in women (Bilezikian 2000), most clinical fractures result in greater morbidity and mortality (Johnell et al 2001). Hip fractures are the most important for health outcomes, quality of life, and costs (Chang et al 2004) with mortality reaching $37.5 \%$ in the year after the fracture (Jiang et al 2005). Vertebral fractures also carry their share of morbidity and mortality in men. Even though most vertebral fractures are painless, they are associated with height loss, reduced quality of life, respiratory dysfunction, social withdrawal (Burger et al 1997; Scane et al 1999) and decreased survival (Lau et al 2008). Finally, a history of low-trauma fracture, including asymptomatic vertebral fracture, increases the risk for hip and other clinical fractures (Melton et al 1999; Klotzbuecher et al 2000). However, despite these alarming statistics and the availability of effective treatment options, osteoporosis continues to be under-recognized in men, with the majority of those with fractures going untreated (Meryn 2005).

\section{Factors contributing to osteoporosis in men}

Osteoporosis in men can be classified as primary or secondary, with primary osteoporosis often divided into idiopathic and age-related based on the age of diagnosis. Primary osteoporosis comprises approximately half the cases in men and is a heterogeneous multi-factorial condition referring to the development of osteoporosis when no secondary cause is identified (Khosla et al 2008). 
Age-related bone loss usually occurs in men over the age of 70 years due to a combination of nutritional and hormonal deficiencies (Khosla et al 2008). The decrease in intestinal calcium absorption and high prevalence of vitamin D insufficiency and deficiency seen in elderly men both contribute to elevated serum parathyroid hormone (PTH) levels and bone loss (Lips 2001). Other potential mechanisms by which sufficient vitamin D levels might preserve bone health are induction of osteoblastogenesis and osteoblastic activity, activation of osteogenic genes, prevention of osteoblast apoptosis and inhibition of bone marrow adipogenesis (Duque et al 2004a, b, 2005). Many other hormonal factors have also been incriminated in the pathophysiology of age-related bone loss in men. Both free or bioavailable testosterone and estradiol levels decline with age due to increased serum sex-hormone binding globulin (SHBG) levels and failure of the hypothalamic-pituitary-testicular axis to compensate (Khosla et al 1998; Orwoll et al 2006). Although cumulating evidence supports a dominant role of estrogen in maintaining bone mass in men, testosterone also contributes (Falahati-Nini et al 2000; Leder et al 2003; Amin et al 2006). Age-related decreases in insulin-like growth factor 1 (IGF-1) and increases in insulin-like growth factor binding protein 2 (IGFBP-2) levels may also impair bone formation directly or via an increase in serum SHBG levels (Amin et al 2004, 2007). On the other hand, $85 \%$ of cases of secondary osteoporosis in men are explained by glucocorticoid use, hypogonadism, and excessive alcohol intake (Ebeling 1998, 2008). These factors are present in the majority of younger men with osteoporosis (Orwoll and Klein 2001) and may be superimposed on primary osteoporosis (Khosla et al 2008).

\section{Pattern of bone loss in men - importance of reduced bone formation on trabecular and cortical bone loss}

Both trabecular and cortical bone loss contribute to an age-related reduction in bone mass. Trabecular bone, predominantly found in the vertebrae, begins to decline before midlife in both sexes, but to a lesser extent in men, with $42 \%$ of trabecular bone being lost before age 50 (Riggs et al 2008). In contrast, cortical bone mass remains relatively stable until midlife, then decreases linearly in both men and women, with the decline being greater in females (Riggs et al 2008). Cortical bone loss occurs later in life from around the age of 65 years in men, as the total surface available for trabecular remodeling decreases, causing bone remodeling to move from the trabecular to cortical compartment (Seeman 2002). The balance between endosteal bone resorption and simultaneous periosteal apposition determines the net decrease in cortical bone area. Although the amount of endosteal bone lost during aging is similar in men and women, periosteal bone gained is greater in men (Garn et al 1972; Seeman 2002; Ahlborg et al 2003). Structural failure emerges during ageing because periosteal bone formation incompletely offsets fragility produced by bone loss and architectural destruction inside bone.

The pattern of age-related changes in bone structure is an important factor in the pathophysiology of bone loss. In men, trabecular bone loss occurs by reduced bone formation, resulting in trabecular thinning, with maintenance of trabecular number and connectivity. Conversely, bone resorption is the predominant mechanism of bone loss in postmenopausal women, resulting in a greater reduction in trabecular number and subsequent loss of connectivity and trabecular perforation (Aaron et al 1987) (Figure 1). Although both trabecular thinning and reduced trabecular number are associated with lower bone density, the latter has the greatest impact on bone strength (Silva and Gibson 1997), explaining in part the lower lifetime risk of fractures in men.

\section{Current management of osteoporosis in men}

\section{Preventive measures}

\section{Exercise and falls prevention}

In healthy older men, high-intensity progressive resistance training, weight-bearing impact exercise, or the combination of the two, increased bone mineral density (BMD) compared with controls (Kukuljan et al 2006). Although clinical trials have not yet shown that these BMD changes translate into reduced fracture risk, observational data suggests that older men who maintain an active lifestyle have a lower fracture risk (Michaelsson et al 2007). Meta-analyses of trials in older adults show that balance and strengthening exercises reduce the risk of falls (Carter et al 2001; Lord et al 2003), and given that a propensity to fall puts people with osteoporosis at greater risk for fracture, falls prevention strategies should be implemented (Tinetti 2003).

\section{Calcium and vitamin D}

Although data on the benefit of calcium and vitamin D on fracture prevention are inconsistent, a recent systematic review of 17 randomized trials involving over 50,000 participants showed that calcium alone or in combination with vitamin D reduces osteoporotic fractures by $12 \%$ among both men and women aged over 50 (Tang et al 2007). When analysis was performed on the 8 trials $(n=4,508)$ that reported a compliance rate of at least $80 \%$, the risk reduction was doubled (24\%). The treatment effect was also greater 
(a)

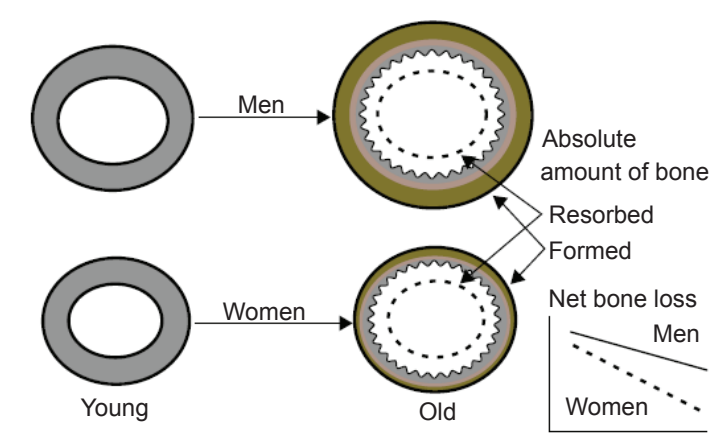

(b)

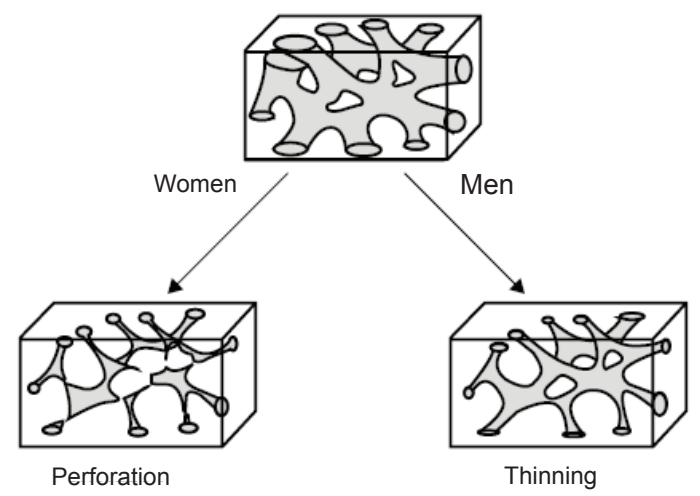

Figure I Gender differences in pattern of cortical (a) and trabecular (b) bone loss resulting in trabecular and cortical thinning in men and increased cortical porosity and trabecular perforation in women. Reproduced with permission from Seeman E. 2002. Pathogenesis of bone fragility in women and men. Lancet, 359:I84I-50. Copyright (C) 2002 Elsevier.

when at least 1,200 $\mathrm{mg}$ of calcium and $800 \mathrm{IU}$ of vitamin D were taken. Vitamin D doses of at least 800 IU daily are therefore recommended, with the goal of maintaining a serum 25-hydroxyvitamin D level $\geq 30 \mathrm{ng} / \mathrm{mL}(75 \mathrm{nmol} / \mathrm{L})$ (Vieth et al 2001).

\section{Pharmacotherapy}

Pharmacological agents have not been as well studied in men with osteoporosis as in women, and only a few treatments have been approved for use in men. These include bisphosphonates and teriparatide.

\section{Bisphosphonates}

Bisphosphonate therapy has been shown to be effective in increasing BMD in men with primary osteoporosis, as well as in men with secondary osteoporosis, including hypogonadism and glucocorticoid-induced osteoporosis (Orwoll et al 2000; Ringe et al 2006). Although most trials of oral bisphosphonates in men have been either underpowered or not primarily designed to assess their effect on fracture incidence, some trials showed a significant $60 \%-88 \%$ reduction in the occurrence of new radiologic vertebral fractures (Orwoll et al 2000; Ringe et al 2006). Although the increase in BMD with bisphosphonate therapy is similar in men and women (Ho et al 2000) and could therefore theoretically translate into a reduction of fracture risk similar to the one observed in women, more data are required to ascertain the benefits of oral bisphosphonates on non-vertebral and hip fractures in men. Zoledronic acid is a potent intravenously administered bisphosphonate whose effects on fracture risk been assessed in a recent randomized placebo-controlled trial involving elderly men and women who had recently suffered a hip fracture (Lyles et al 2007). Yearly administration of $5 \mathrm{mg}$ of zoledronic acid for a median of 1.9 years within 3 months of the fracture reduced the occurrence of overall new clinical fractures and mortality, but not hip fractures. Bisphosphonates are generally well tolerated. However, both intravenous and oral bisphosphonates have been linked in rare cases to osteonecrosis of the jaw, although current limited data suggest no clear increase in the risk of this complication in patients with osteoporosis (Bilezikian 2006). Rare case reports of atypical femoral diaphyseal fractures in patients on bisphosphonate therapy have also recently emerged in the literature and raise concerns about the long-term safety of this treatment in some individuals (Goh et al 2007; Lenart et al 2008; Visekruna et al 2008). However, more data are required on these atypical fractures.

\section{Teriparatide as a new option for the treatment of osteoporosis in men} Teriparatide: why is it different?

Anticatabolic therapies such as bisphosphonates act by inhibiting osteoclast activity causing a decrease in bone resorption and depth of resorption cavities. Because bone remodeling is a coupled process, this decrease in osteoclast activity is accompanied by a decrease in osteoblast activity (Balena et al 1993; Draper et al 1996). This low turnover state leads to an improvement in BMD by increasing the time for matrix mineralization (Meunier and Boivin 1997). Anticatabolic therapies halt bone loss but do not add new 
bone, nor do they restore disrupted microarchitecture. In severe cases of osteoporosis, putting a stop to further bone loss may not be enough to prevent further fractures. In these cases, treatments that stimulate bone formation and reverse skeletal deterioration may provide a valuable treatment option (National Cancer Institute 2001). In men, where decreased bone formation is an important etiological factor, an anabolic treatment seems a logical approach. Teriparatide is the only anabolic agent currently approved for treatment of osteoporosis in men.

\section{Molecular structure of parathormone and teriparatide}

The native hormone secreted by the parathyroid gland chief cell is human parathyroid hormone [hPTH (1-84)], a singlechain polypeptide with 84 amino acids (Quattrocchi and Kourlas 2004). The knowledge of the molecular structure of PTH allowed the production of hPTH (1-84) for treatment in humans. Moreover, the discovery that the N-terminal 34 amino acid portion of the native PTH molecule could fully activate the PTH/PTHrP receptor (Reeve et al 1980) led to the generation of pharmacological products comprising only this portion, such as hPTH (1-34) and recombinant human PTH [rhPTH (1-34)]. Teriparatide is the generic name for all PTH (1-34) molecules.

\section{Anabolic effects of teriparatide on bone}

Continuous high circulating PTH levels versus intermittent peaks of PTH have opposite effects on bone metabolism. The former has catabolic effects on bone as shown in people with primary hyperparathyroidism whereas administration of low-dose $(20 \mu \mathrm{g} / \mathrm{d})$, intermittent PTH, has an anabolic effect (Tam et al 1982). Although there have been advances in understanding the molecular and cellular events associated with activation of the PTH receptor in bone, the mechanism of action of teriparatide remains incompletely elucidated. Based on bone marker studies, teriparatide increases both bone formation and resorption. However, in the first 3 months of treatment, there is a period known as "the anabolic window" where PTH stimulates bone formation to a greater extent than bone resorption, suggesting that teriparatide could initially induce bone apposition without prior bone resorption through modeling-based formation (Dempster 2001; Bilezikian 2008). After 3-6 months of teriparatide treatment, the bone remodeling rate is globally increased, with bone formation favored over bone resorption resulting in a net gain of bone deposited in each basic multicellular unit (BMU). Teriparatide's effect on bone formation is mediated by an increase in the number of osteoblasts via activation of osteoprogenitor differentiation and prevention of osteoblast apoptosis (Nishida et al 1994; Jilka et al 1999). Its anabolic effect on bone could also be indirect, through induction of IGF-1 synthesis in osteoblasts and downregulation of growth factor antagonists, such as sclerostin (Canalis et al 1989; Miyakoshi et al 2001; Bellido 2006).

\section{Safety and tolerability}

\section{Frequent adverse effects}

Adverse events reported during large phase III trials with teriparatide have generally been mild (Orwoll et al 2003). Most frequent adverse events associated with teriparatide $20 \mu \mathrm{g}$ sc daily were dizziness and leg cramps, and these occurred in fewer than $10 \%$ of treated patients. Injection site hypersensitivity occurred in a small number of patients. Allergic reactions, including dyspnea, urticaria, and chest pain, occurred in fewer than 1 in 1000 teriparatide recipients (Gold et al 2006).

\section{Hypercalcemia and hypercalciuria}

Six percent of men experienced mild transient hypercalcemia in phase III trials. It appeared generally 4-6 hours after teriparatide administration and resolved within 24 hours (Orwoll et al 2003). If hypercalcemia occurs, it is generally recommended to reduce calcium intake to $1,000 \mathrm{mg}$ daily or less or to decrease the dose or frequency of teriparatide. Monitoring of serum calcium is not considered to be a routine requirement during treatment with teriparatide. However, measuring serum calcium at baseline and after a month of therapy could be a good practice (Stroup et al 2003; Hodsman et al 2006). Likewise, a recent study evaluating the effect of teriparatide on urinary calcium at 1, 6, and 12 months in two large placebo-controlled trials (Neer et al 2001; Orwoll et al 2003) showed that increases in urinary calcium excretion were small and that less than $1 \%$ of the participants required a change in calcium or teriparatide dose due to hypercalciuria (Miller et al 2007). Since subjects with impaired renal function or with a history of kidney stones were excluded in these trials, it might be considered to monitor urinary calcium in patients with hypercalciuria at baseline or with a history of urolithiasis; however, no firm guidelines have been established on the follow-up of this rare adverse effect (Hodsman et al 2006; Miller et al 2007).

\section{Osteosarcoma}

So far, only one case of osteosarcoma associated with teriparatide has been reported in humans (Harper et al 2006). 
However, causality between teriparatide and osteosarcoma in this patient has not been established, as this was a single case among more than 300,000 patients worldwide treated with teriparatide, which is similar to the background incidence of osteosarcoma in the general population of men and women over 60 years of age. The fact that this case of osteosarcoma was detected early in the course of teriparatide also led to speculation it was pre-existing. Nevertheless, close monitoring for incident cases of osteosarcoma in patients treated with teriparatide should be continued. In addition, teriparatide treatment should be avoided in patients at increased baseline risk for osteosarcoma, such as those with Paget's disease, unexplained elevations in alkaline phosphatase, or prior radiation therapy involving the skeleton. Its use should also be limited to two years because safety and efficacy for longer periods have not been evaluated (Stroup et al 2008).

\section{Efficacy studies of teriparatide in men Effects of teriparatide on biochemical bone markers}

Markers of bone formation include bone specific alkaline phosphatase (ALP), osteocalcin (OC), and C-terminal and $\mathrm{N}$-terminal propeptides of type one procollagen (PICP and PINP), whereas urinary free pyridinoline (PYD), free deoxpyridinoline (fDPD), and N-telopeptide (NTX), as well as serum $\mathrm{C}$-telopeptide, are markers of bone resorption. The measurement of bone markers in clinical trials have helped better understand the mechanism of action of teriparatide and to determine the role of these markers in the prediction and assessment of the response to treatment in both men and women with osteoporosis. Three studies conducted in men with osteoporosis have evaluated the effects of teriparatide on bone markers (Kurland et al 2000; Orwoll et al 2003; Finkelstein et al 2006). Markers of bone formation (bone ALP and PICP) and resorption (NTX and FDPD) were measured at baseline, 1, 3, 6, and 12 months following treatment with teriparatide 20 or $40 \mu \mathrm{g}$ daily in 437 men with primary osteoporosis or osteoporosis due to primary hypogonadism (Orwoll et al 2003). Teriparatide caused significant dose-dependent increases in both markers of bone formation and resorption. One month after teriparatide $20 \mu \mathrm{g}$ daily, PICP levels reached their maximum ( $\sim 30 \%$ increase from baseline) while the ratios of urine NTX and fDPD corrected for creatinine were only marginally increased. Similar greater increments of markers of bone formation over bone resorption were reported in the first 1-3 months of treatment when PICP, OC, and P1NP were measured (Kurland et al 2000; Finkelstein et al 2006). Changes in bone resorption markers after teriparatide treatment were similar between studies with peak levels at 6-12 months. Of interest is the distinct pattern of response between bone formation markers in the study by Orwoll et al. As opposed to PICP, the increment of bone ALP was gradual, reaching a peak at 6 months (Figure 2). These findings suggest that different bone formation markers provide information on different aspects of osteoblast function and might not be interchangeable (Orwoll et al 2003).

Two studies have provided insight on the possible role of bone markers to predict the response to teriparatide (Kurland et al 2000; Dobnig et al 2005). The first study, conducted in men with idiopathic osteoporosis, found that the change in OC at 3 months together with baseline PYD contributed $70 \%$ to the variance in lumbar spine BMD after 18 months of teriparatide treatment (Kurland et al 2000). In postmenopausal women, early increases in bone formation markers, and especially bone ALP, correlated with improvements in bone structure after 22 months of rPTH (1-34) (Dobnig et al 2005). However, no studies in men have assessed the role of bone markers to predict bone structure.

In summary, greater and earlier increases in bone formation markers compared with bone resorption markers after teriparatide therapy suggest that bone gain initially results from modeling-based bone formation without prior bone resorption. Later, stimulation of bone remodeling and in particular, bone formation, by teriparatide, provides additional bone gain. This is in contrast with reductions in bone markers typical of anti-resorptive therapy. As for bisphosphonates, it appears that bone markers could be useful as predictors of response to teriparatide treatment, particularly PINP and PICP.

\section{Effects of teriparatide on BMD and fracture risk (Table I)}

Two main studies have evaluated the effect of teriparatide on BMD in men (Kurland et al 2000; Orwoll et al 2003). In the first study, 23 men aged between 30 and 69 years with idiopathic osteoporosis and with or without a previous fracture (prevalence of fracture of $70 \%$ and $90 \%$ in the placebo and treatment groups, respectively) were randomized to either placebo or $400 \mathrm{IU}(25 \mu \mathrm{g})$ of hPTH (1-34) for 18 months (Kurland et al 2000). BMD was measured at baseline and every 6 months at the lumbar spine, hip and radius. A linear increase in lumbar spine BMD was observed in the treatment group and was already significant at 6 months $(4.8 \pm 2.0 \%$ at 6 months and $13.5 \pm 3.0 \%$ at 18 months), whereas no significant change was remarkable in the placebo 

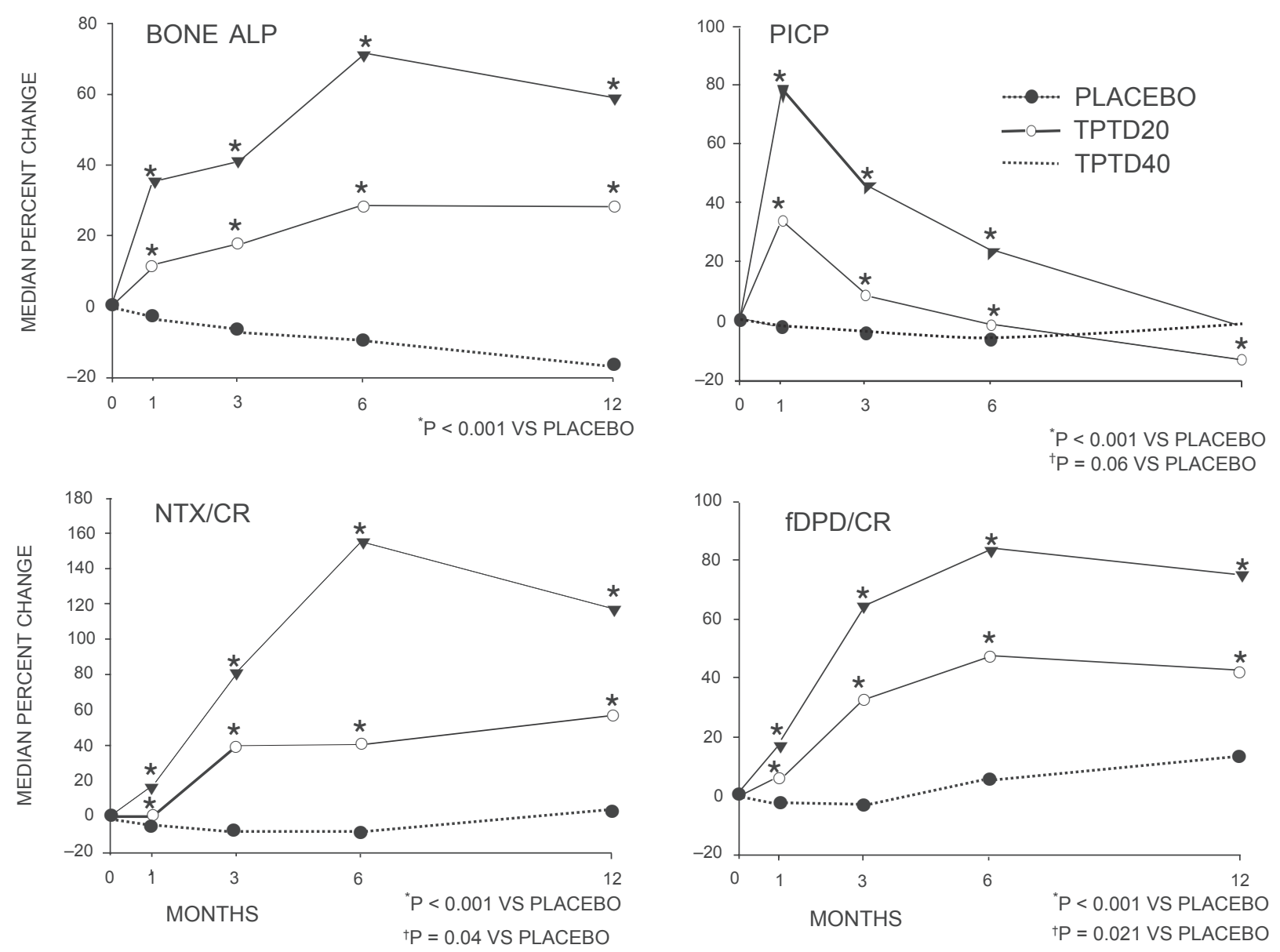

Figure 2 Effects of teriparatide on bone formation and resorption markers. Bone ALP peaked at 6 months, whereas PICP peaked at I month. Both bone resorption markers NTX/CR and fDPD/CR reached maximum levels at 6 months. Reproduced from Orwoll ES, Scheele WH, Paul S, et al 2003. The effect of teriparatide [human parathyroid hormone (I-34)] therapy on bone density in men with osteoporosis.J Bone Miner Res, 18:9-17. With permission of the American Society for Bone and Mineral Research. ${ }^{*} \mathrm{p}<0.00 \mathrm{I}$ for comparisons between TPTD20 and TPTD40 groups vs placebo at I, 3, 6, and 12 months. ${ }^{\dagger} \mathrm{p}$-value for comparisons between TPTD20, and TPTD40 groups vs placebo at I, 3,6, and 12 months (the p-value is indicated at the bottom of each figure).

Abbreviations: bone ALP, bone alkaline phosphatase; PICP, procollagen I carboxy-terminal; NTX/CR, urinary N-telopeptide/creatinine ratio; fDPD/CR, free deoxypyridinoline/creatinine ratio;TPTD20, teriparatide $20 \mu \mathrm{g}$;TPTD40, teriparatide $40 \mu \mathrm{g}$.

group. In contrast, the increase in BMD at the femoral neck in men treated with teriparatide was slower, only reaching significance at 18 months $(2.9 \pm 1.5 \% ; \mathrm{p}<0.05)$. Finally, the treatment group experienced a small and non-significant $1.2 \pm 0.6 \%$ decline in BMD at the $1 / 3$ site of the radius compared with baseline. These results were reproduced in a study involving 437 men aged 30-85 years with primary osteoporosis or primary hypogonadism treated for a median of 11 months with either rPTH (1-34) 20 or $40 \mu \mathrm{g}$ daily or placebo. Although the increase in lumbar spine BMD was less in this study, it was already significant at 3 months (Orwoll et al 2003) (Figure 3). The response to teriparatide treatment was independent of gonadal status, alcohol intake or age.

None of these studies was specifically designed to address the effect of teriparatide on fracture risk in men. To our knowledge, the only study that evaluated this endpoint is a follow-up of the previously mentioned study conducted by Orwoll et al (Kaufman et al 2005). Eighty-one percent of the initial cohort of 437 hypogonadal or eugonadal men with osteoporosis were enrolled in the 30-month followup study. Of these, $41 \%$ had known vertebral fractures at baseline. Baseline radiographs of the thoraco-lumbar spine before initiation of teriparatide were compared with those 18 months after discontinuation of therapy in 279 subjects. There was a trend for the risk of new vertebral fractures to be reduced by $51 \%(\mathrm{p}=0.07)$ in men who received teriparatide, corresponding to an absolute risk reduction (RR) of $6 \%$. Of particular interest is the $83 \%$ reduction in the incidence of moderate or severe vertebral fractures in the combined teriparatide groups (absolute RR 5.7\%; $p=0.01$ ). Of the 114 men with vertebral fractures at baseline, the 
Table I Studies evaluating the efficacy of teriparatide in men with osteoporosis

\begin{tabular}{|c|c|c|c|c|c|c|c|c|}
\hline $\begin{array}{l}\text { First } \\
\text { author } \\
\text { year }\end{array}$ & $\mathbf{n}$ & $\begin{array}{l}\text { Baseline } \\
\text { characteristics }\end{array}$ & $\begin{array}{l}\text { Treatment } \\
\text { duration }\end{array}$ & Treatment & $\begin{array}{l}\text { Percent } \\
\text { change in BMD } \\
\text { at the lumbar } \\
\text { spine }^{\mathrm{a}}\end{array}$ & $\begin{array}{l}\text { Percent change } \\
\text { in BMD at the } \\
\text { femoral neck }^{\mathrm{a}}\end{array}$ & $\begin{array}{l}\text { Percent change } \\
\text { in } B M D \text { at the } \\
I / 3 \text { site of the } \\
\text { radius }^{\mathrm{a}}\end{array}$ & $\begin{array}{l}\text { Vertebral } \\
\text { fracture } \\
\text { reduction }\end{array}$ \\
\hline \multirow[t]{2}{*}{$\begin{array}{l}\text { Kurland } \\
2000\end{array}$} & 23 & $\begin{array}{l}\text { - Idiopathic } \\
\text { osteoporosis } \\
\text { - Low bone }\end{array}$ & $18 \mathrm{mo}$ & $\begin{array}{l}\text { Teriparatide } \\
400 \mathrm{lU} / \mathrm{d} \\
(25 \mu \mathrm{g})\end{array}$ & $13.5 \pm 3.0^{c}$ & $2.9 \pm 1.5^{c}$ & $-1.2 \pm 0.6^{c}$ & $\begin{array}{l}\text { - Insufficient } \\
\text { power }\end{array}$ \\
\hline & & $\begin{array}{l}\text { turnover } \\
\text { - Fracture history } \\
\text { or back pain } \\
\text { - LS T-score }-3.4 \\
\text { - FN T-score -2.0 }\end{array}$ & & Placebo & NS & NS & NS & \\
\hline \multirow[t]{3}{*}{$\begin{array}{l}\text { Orwoll } \\
2003\end{array}$} & 437 & $\begin{array}{l}\text { - Hypogonadal } \\
\text { (49\%) or }\end{array}$ & II mo (median) & $\begin{array}{l}\text { Teriparatide } \\
20 \mu \mathrm{g} / \mathrm{d}\end{array}$ & $5.9(5.2,6.6)^{c, d}$ & I.5 $(0.9,2.2)^{c, d}$ & $-0.5(-0.8,-0.1)$ & $\begin{array}{l}-51 \% \text { RRR } \\
\text { fractures }^{h}\end{array}$ \\
\hline & & $\begin{array}{l}\text { eugonadal } \\
\text { - LST-score }-2.2\end{array}$ & & $\begin{array}{l}\text { Teriparatide } \\
40 \mu \mathrm{g} / \mathrm{d}\end{array}$ & $9.0(7.9,10.1)^{c, d}$ & $2.9(1.9,4.0)^{\mathrm{c.d} d}$ & $-0.6(-0.9,-0.2)$ & $\begin{array}{l}-83 \% \text { RRR } \\
\text { moderate/ }\end{array}$ \\
\hline & & - FN T-score -2.7 & & Placebo & NS & NS & NS & $\begin{array}{l}\text { severe } \\
\text { fractures }^{h}\end{array}$ \\
\hline \multirow[t]{3}{*}{$\begin{array}{l}\text { Finkelstein } \\
2003\end{array}$} & 83 & $\begin{array}{l}\text { - Primary } \\
\text { osteoporosis }\end{array}$ & 30 mo (median) & $\begin{array}{l}\text { Teriparatide } \\
40 \mu g / d^{b}\end{array}$ & I8.I $(|4.9,2| .3)^{\mathrm{e}, \mathrm{f}}$ & $9.7(6.1,13.4)^{\mathrm{e}, \mathrm{f}}$ & $-0.8(-2.3,0.6)^{e, f}$ & - \\
\hline & & $\begin{array}{l}\text { - } \mathrm{LS} \text { or } \mathrm{FN} \\
\text { T-score } \leq-2.0\end{array}$ & & $\begin{array}{l}\text { Alendronate } \\
10 \mathrm{mg} / \mathrm{d}\end{array}$ & $7.9(6.3,9.4)^{\mathrm{e}, g}$ & $3.2(1.5,4.8)^{\mathrm{e}}$ & $1.0(0.2,1.8)^{\mathrm{e}}$ & \\
\hline & & & & Both ${ }^{b}$ & $14.8(|2.4,| 7.3)^{f, g}$ & $6.2(4.0,8.4)^{f}$ & I.0 $(-0.1,2.1)^{f}$ & \\
\hline
\end{tabular}

aean percentage change in BMD \pm SEM or mean percentage change in $\mathrm{BMD}(95 \% \mathrm{Cl})$ at the study endpoint.

'Teriparatide was begun at month 6 .

${ }^{c} \mathrm{p}<0.05$, teriparatide $20 \mu \mathrm{g} / \mathrm{d}$ or $40 \mu \mathrm{g} / \mathrm{d}$ vs placebo.

${ }_{\mathrm{d}}^{\mathrm{d}}<0.05$, teriparatide $20 \mu \mathrm{g} / \mathrm{d}$ vs $40 \mu \mathrm{g} / \mathrm{d}$.

${ }^{\mathrm{e}} \mathrm{p}<0.05$, teriparatide $40 \mu \mathrm{g} / \mathrm{d}$ vs alendronate.

${ }^{\mathrm{f}} \mathrm{p}<0.05$, teriparatide $40 \mu \mathrm{g} / \mathrm{d}$ vs combination alendronate $10 \mathrm{mg} / \mathrm{d}$ and teriparatide $40 \mu \mathrm{g} / \mathrm{d}$.

${ }_{\mathrm{g}}^{\mathrm{p}}<0.05$, alendronate $10 \mathrm{mg} / \mathrm{d}$ vs combination alendronate $10 \mathrm{mg} / \mathrm{d}$ and teriparatide $40 \mu \mathrm{g} / \mathrm{d}$.

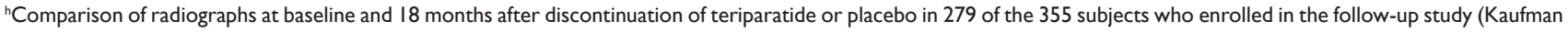
et al 2005). At that time, $36 \%$ and $25 \%$ of the men who were previously in the placebo and combined teriparatide arms, respectively, were receiving an anti-osteoporosis drug. Bisphosphonates accounted for $75 \%$ of osteoporosis therapy and testosterone was the second most common.

Abbreviations: LS, lumbar spine; FN, femoral neck; BMD, bone mineral density; Mo, months; NS, not significant; RRR, relative risk reduction.

absolute RR for a new vertebral fracture was 13\% in those assigned to the treatment group and no participant in this group experienced a moderate or severe fracture $(p=0.002$ vs placebo). This study was not powered to evaluate the effect of treatment on the incidence of non-vertebral or hip fractures.

\section{Combination therapy with teriparatide and alendronate}

Since teriparatide increases both bone formation and resorption, the combination with an anti-resorptive agent could theoretically have synergistic effects on BMD. However, studies in both men and women have clearly shown that bisphosphonates impair the ability of teriparatide or PTH (1-84) to increase BMD (Neer et al 2002; Black et al 2003; Finkelstein et al 2003). The relative efficacies of alendronate, teriparatide or a combination of the two were assessed in a study of 83 men with low BMD (Finkelstein et al 2003). Participants were randomly assigned to receive alendronate $10 \mathrm{mg} /$ day, PTH $40 \mu \mathrm{g} / \mathrm{day}$, or both treatments for 30 months. The PTH-alone group had BMD increases of $18.1 \%$ at the posteroanterior spine and $9.7 \%$ at the femoral neck. These increases were significantly greater than those observed in both the alendronate arm (7.9\% and 3.2\%, respectively) and in the combination therapy arm (14.8\% and $6.2 \%$, respectively). These findings raise the possibility that bone resorption is required for teriparatide to increase bone formation. Measurement of bone markers in this study revealed that alendronate impaired the ability of teriparatide to increase both bone formation and bone resorption markers, therefore supporting this hypothesis (Finkelstein et al 2006). Indeed, prior bone resorption may release preformed growth factors necessary to trigger the anabolic effect of teriparatide (Oreffo et al 1989). However, a direct effect of 


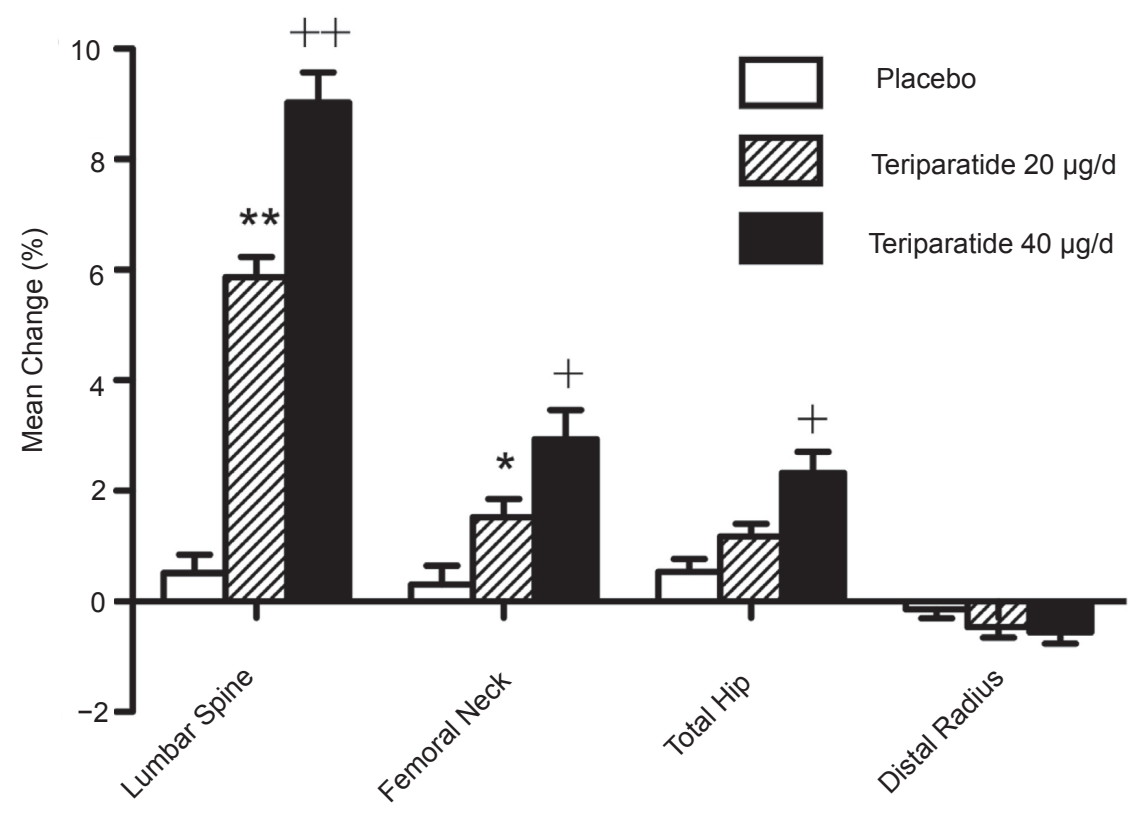

Figure 3 Mean percentage changes in bone mineral density at the lumbar spine, femoral neck, total hip and distal radius following a median of II months of teriparatide 20 or $40 \mu \mathrm{g} / \mathrm{d}$ vs placebo. Bars represent the SEM. Adapted from Orwoll ES, Scheele WH, Paul S, et al 2003. The effect of teriparatide [human parathyroid hormone (I-34)] therapy on bone density in men with osteoporosis.J Bone Miner Res, 18:9-17. With permission of the American Society for Bone and Mineral Research.

$*_{\mathrm{p}}<0.05$, teriparatide $20 \mu \mathrm{g} / \mathrm{d}$ vs placebo.

$* * \mathrm{p}<0.00$ I, teriparatide $20 \mu \mathrm{g} / \mathrm{d}$ vs placebo.

${ }^{+} \mathrm{p}<0.05$, teriparatide $20 \mu \mathrm{g} / \mathrm{d}$ vs teriparatide $40 \mu \mathrm{g} / \mathrm{d}$.

${ }^{++} \mathrm{P}<0.00$ I, teriparatide $20 \mu \mathrm{g} / \mathrm{d}$ vs teriparatide $40 \mu \mathrm{g} / \mathrm{d}$.

alendronate on osteoblasts cannot be excluded and it is still possible that teriparatide stimulates directly bone formation independently of its effect on bone resorption through mechanisms previously explained. In conclusion, these data indicate teriparatide should be initiated as monotherapy, because combination with anti-resorptive agents attenuates its anabolic effect.

\section{Effect of previous bisphosphonate therapy on efficacy of teriparatide}

Given that teriparatide is costly and generally approved as second-line therapy in most countries, the great majority of men with osteoporosis encountered in clinical practice will have already received a course of bisphosphonates prior to initiation of teriparatide. The ensuing important question is whether previous treatment with bisphosphonates reduces the efficacy of teriparatide. Finkelstein et al (2006) compared the increase in bone formation and bone resorption markers following teriparatide started at baseline for 30 months or preceded by 6 months of alendronate $10 \mathrm{mg}$ daily in $63 \mathrm{men}$ with low bone mass. Alendronate clearly reduced the ability of teriparatide to increase both bone formation and resorption markers. In the only study including men (29 men and 35 women) with osteoporosis, Handler retrospectively compared the effect of 18-24 months of teriparatide on
BMD in patients previously treated with iv bisphosphonates (group 1, $\mathrm{n}=36$ ) or oral bisphosphonates (group 2, $\mathrm{n}=16$ ) vs treatment naïve patients (group 3, $\mathrm{n}=12$ ) (Handler 2008). Annualized average BMD gain, assessed by spine computerized vertebral tomography (QCT), was 7\%, 4\%, and $16 \%$ in groups 1,2 , and 3, respectively. Patients who received iv or oral bisphosphonates were also more likely than treatment naïve patients to be non-responders $(14 \%$ and $25 \%$ vs $0 \%$, respectively) defined as further bone loss or $<1 \%$ annualized gain under treatment. Of interest, the time lag between the last dose of bisphosphonate and initiation of teriparatide positively influenced the response to teriparatide. Although current evidence in men is scarce, it is consistent with a blunting of the effect of teriparatide on bone markers and BMD when administered after a course of bisphosphonates.

\section{Initiation of therapy after discontinuation of teriparatide}

Because of the osteosarcoma concerns, teriparatide therapy is currently approved for 18 to 24 months, depending on the country. After this period, switching to a bisphosphonate is recommended to maintain and perhaps increase the gains obtained during teriparatide treatment. Indeed, rapid loss of BMD occurred after discontinuation of teriparatide in 
men with idiopathic osteoporosis (Kurland et al 2004). Furthermore, additional gains in lumbar spine BMD were demonstrated if a bisphosphonate was administrated immediately after cessation of hPTH (1-34), with a 4-fold cumulative increase in lumbar spine BMD at two years in those who took a bisphosphonate compared to those who delayed bisphosphonate therapy or who received no treatment ( $23.6 \%, 11.1 \%$, and $5.5 \%$, respectively). Noteworthy, the use of teriparatide for a mean of 22 months did not appear to blunt the ability of bone to subsequently respond to a bisphosphonate. These findings are interesting and suggest that when bisphosphonates are initiated after a course of teriparatide, they enhance mineralization of the newly formed and less mineralized bone produced by the action of teriparatide on osteoblasts (Kurland et al 2004).

\section{Monitoring of treatment}

Although dual X-ray absorptiometry (DXA) is considered to be the gold standard for monitoring the response to osteoporosis treatment, the best method of monitoring a patient's response to anabolic drug treatment is still being debated. Within the first year of therapy using teriparatide, BMD typically increases at the spine and to a lesser extent at the proximal femur. Conversely, decreases in BMD may be observed in areas of predominantly cortical bone, such as the distal radius. The latter may result from a relatively greater increase in bone diameter compared with cortical thickness (Stroup et al 2008). Of note is the finding that increased lumbar spine BMD accounts for only $30 \%-41 \%$ of the vertebral fracture risk reduction following teriparatide therapy, suggesting that improvements in non-BMD determinants of bone strength, such as increases in bone thickness and diameter, also play an important role (Chen et al 2006). Through stimulation of bone remodeling, teriparatide could also improve bone quality by reducing the amount of microdamage, and by removing highly mineralized bone.

Despite the limitations of DXA, current recommendations regarding monitoring of teriparatide therapy suggest annual or 2-yearly DXA scans, similar to the evaluation of response to anti-catabolic agents. QCT is an attractive technique that could provide complementary information on the effects of teriparatide on bone microarchitecture and structure. However, the lack of availability, high radiation exposure and high coefficient of variation outside clinical trials currently limit the use of this modality in the clinical setting. Measurement of serum markers of bone formation, particularly PINP or PICP at baseline and after 3-6 months of treatment, may provide another method of monitoring the efficacy of teriparatide treatment and help assess medication adherence (Kurland et al 2000; Eastell et al 2006). It is, however, important to remember that bone markers are subject to intra-individual variability (Ebeling and Akesson 2001) especially if not sampled correctly or when measured in routine clinical practice. Therefore, results should be interpreted with caution and take into account these possible limitations.

\section{Patient perspective: compliance and reduction of back pain}

Compliance with daily injections of teriparatide as well as patient satisfaction and acceptability of this treatment were assessed in a study of 116 men and women with osteoporosis (Adachi et al 2007). Reported compliance was excellent with $89 \%$ and $82 \%$ of the participants still taking the medication at 6 months and 18 months, respectively. Globally, patient satisfaction with teriparatide was $73 \%$ at 3 months, $77 \%$ at 6 months, and $86 \%$ at 18 months. The compliance with teriparatide in this study is similar to the one reported in clinical trials of teriparatide and is in contrast with the $50 \%-75 \%$ discontinuation rate observed after 1 year of oral bisphosphonate therapy (McCombs et al 2004; Cramer et al 2005). This study also demonstrates that the initial fear of injections is usually overcome after a few months of treatment and does not impede patient satisfaction.

Another advantage of teriparatide over bisphosphonates is the reduction of back pain. A meta-analysis comprising 4 randomized and controlled trials, of which 1 was performed in men with idiopathic or hypogonadal osteoporosis (Orwoll et al 2003), showed that severe back pain was reduced by $61 \%$ in the pooled teriparatide vs the pooled comparators trials (placebo, alendronate, or hormonotherapy) (Nevitt et al 2006). The risk reduction for any back pain was evident after only 6 months of teriparatide. In particular, the results were not different across trials, supporting a similar effect in both men and women. This study also suggests that the beneficial effect of teriparatide on back pain may be explained by a reduction in vertebral fractures.

\section{Conclusion}

Reduced bone formation with resulting thinning of trabecular bone in excess of cortical bone in men with osteoporosis makes teriparatide an especially attractive treatment for men. However, until further studies demonstrate its efficacy on reducing non-vertebral and hip fractures and the cost of teriparatide is reduced, teriparatide should be 
restricted to patients at high risk of an osteoporotic fracture, who are unable to tolerate anti-catabolic therapy, or who have worsening BMD or persistently low BMD, or suffer fractures while receiving anti-catabolic therapy (Stroup et al 2008).

\section{Disclosures}

The authors have no conflicts of interest to declare.

\section{References}

Aaron JE, Makins NB, Sagreiya K. 1987. The microanatomy of trabecular bone loss in normal aging men and women. Clin Orthop Relat Res, 215:260-71.

AdachI JD, Hanley DA, Lorraine JK, et al. 2007. Assessing compliance, acceptance, and tolerability of teriparatide in patients with osteoporosis who fractured while on antiresorptive treatment or were intolerant to previous antiresorptive treatment: an 18-month, multicenter, open-label, prospective study. Clin Ther, 29, 2055-67.

Ahlborg HG, Johnell O, Turner CH, et al. 2003. Bone loss and bone size after menopause. $N$ Engl J Med, 349, 327-34.

Amin S, Riggs BL, Atkinson EJ, et al. 2004. A potentially deleterious role of IGFBP-2 on bone density in aging men and women. $J$ Bone Miner Res, 19:1075-83.

Amin S, Riggs BL, Melton LJ, 3rd, et al. 2007. High serum IGFBP-2 is predictive of increased bone turnover in aging men and women. $J$ Bone Miner Res, 22:799-807.

Amin S, Zhang Y, Felson DT, et al. 2006. Estradiol, testosterone, and the risk for hip fractures in elderly men from the Framingham Study. Am J Med, 119:426-33.

Balena R, Toolan BC, Shea M, et al. 1993. The effects of 2-year treatment with the aminobisphosphonate alendronate on bone metabolism, bone histomorphometry, and bone strength in ovariectomized nonhuman primates. J Clin Invest, 92, 2577-86.

Bellido T. 2006. Downregulation of SOST/sclerostin by PTH: a novel mechanism of hormonal control of bone formation mediated by osteocytes. J Musculoskelet Neuronal Interact, 6:358-9.

Bilezikian JP. 2000. Gender specificity and osteoporosis. J Gend Specif Med, 3:6-12.

Bilezikian JP. 2006. Osteonecrosis of the jaw - do bisphosphonates pose a risk? N Engl J Med, 355:2278-81.

Bilezikian JP. 2008. Combination anabolic and antiresorptive therapy for osteoporosis: opening the anabolic window. Curr Osteoporos Rep, 6:24-30.

Black DM, Greenspan SL, Ensrud KE, et al. 2003. The effects of parathyroid hormone and alendronate alone or in combination in postmenopausal osteoporosis. N Engl J Med, 349:1207-15.

Burge R, Dawson-Hughes B, Solomon DH, et al. 2007. Incidence and economic burden of osteoporosis-related fractures in the United States, 2005-2025. J Bone Miner Res, 22, 465-75.

Burger H, Van Daele PL, Grashuis K, et al. 1997. Vertebral deformities and functional impairment in men and women. $J$ Bone Miner Res, $12: 152-7$.

Canalis E, Centrella M, Burch W, et al. 1989. Insulin-like growth factor I mediates selective anabolic effects of parathyroid hormone in bone cultures. $J$ Clin Invest, 83:60-5.

Carter ND, Kannus P, Khan KM. 2001. Exercise in the prevention of falls in older people: a systematic literature review examining the rationale and the evidence. Sports Med, 31:427-38.

Chang KP, Center JR, Nguyen TV, et al. 2004. Incidence of hip and other osteoporotic fractures in elderly men and women: Dubbo Osteoporosis Epidemiology Study. J Bone Miner Res, 19:532-6.

Chen P, Miller PD, Delmas PD, et al. 2006. Change in lumbar spine BMD and vertebral fracture risk reduction in teriparatide-treated postmenopausal women with osteoporosis. J Bone Miner Res, 21:1785-90.
Cooper C, Melton LJ 3rd 1992. Epidemiology of osteoporosis. Trends Endocrinol Metab, 3:224-9.

Cramer JA, Amonkar MM, Hebborn A, et al. 2005. Compliance and persistence with bisphosphonate dosing regimens among women with postmenopausal osteoporosis. Curr Med Res Opin, 21:1453-60.

Dempster DW, Zhou H, Cosman F. 2001. PTH treatment directly stimulates bone formation in cancellous and cortical bone in humans. $J$ Bone Miner Res, 16(S1):S179.

Dobnig H, Sipos A, Jiang Y, et al. 2005. Early changes in biochemical markers of bone formation correlate with improvements in bone structure during teriparatide therapy. J Clin Endocrinol Metab, 90:3970-7.

Draper MW, Flowers DE, Huster WJ, et al. 1996. A controlled trial of raloxifene (LY139481) HCl: impact on bone turnover and serum lipid profile in healthy postmenopausal women. J Bone Miner Res, 11:835-42.

Duque G, El Abdaimi K, Henderson JE, et al. 2004a. Vitamin D inhibits Fas ligand-induced apoptosis in human osteoblasts by regulating components of both the mitochondrial and Fas-related pathways. Bone, 35:57-64.

Duque G, Macoritto M, Dion N, et al. 2005. 1,25(OH)2D3 acts as a bone-forming agent in the hormone-independent senescenceaccelerated mouse (SAM-P/6). Am J Physiol Endocrinol Metab, 288:E723-30.

Duque G, Macoritto M, Kremer R. 2004b. Vitamin D treatment of senescence accelerated mice (SAM-P/6) induces several regulators of stromal cell plasticity. Biogerontology, 5, 421-9.

Eastell R, Krege JH, Chen P, et al. 2006. Development of an algorithm for using PINP to monitor treatment of patients with teriparatide. Curr Med Res Opin, 22:61-6.

Ebeling PR. 1998. Osteoporosis in men. New insights into aetiology, pathogenesis, prevention and management. Drugs Aging, 13:421-34.

Ebeling PR. 2008. Clinical practice. Osteoporosis in men. N Engl J Med, 358:1474-82.

Ebeling PR, Akesson K. 2001. Role of biochemical markers in the management of osteoporosis. Best Pract Res Clin Rheumatol, 15:385-400

Falahati-Nini A, Riggs BL, Atkinson EJ, et al. 2000. Relative contributions of testosterone and estrogen in regulating bone resorption and formation in normal elderly men. $J$ Clin Invest, 106:1553-60.

Finkelstein JS, Hayes A, Hunzelman JLet al. 2003. The effects of parathyroid hormone, alendronate, or both in men with osteoporosis. N Engl J Med, 349:1216-26.

Finkelstein JS, LederBZ, Burnett SMet al. 2006. Effects of teriparatide, alendronate, or both on bone turnover in osteoporotic men. $J$ Clin Endocrinol Metab, 91:2882-7.

Garn SM, Frisancho AR, Sandusky ST, et al. 1972. Confirmation of the sex difference in continuing subperiosteal apposition. Am J Phys Anthropol, 36:377-80.

Goh SK, Yang KY, Koh JS, et al. 2007. Subtrochanteric insufficiency fractures in patients on alendronate therapy: a caution. $J$ Bone Joint Surg Br, 89:349-53.

Gold DT, Pantos BS, Masica DN, et al. 2006. Initial experience with teriparatide in the United States. Curr Med Res Opin, 22:703-8.

Handler RP. 2008. Prior bisphosphonate therapy of osteoporosis attenuates and blocks response to subsequent parathyroid hormone. J Clin Rheumatol, 14:122-4.

Harper KD, Krege JH, Marcus R, et al. 2006. Comments on initial experience with teriparatide in the United States. Curr Med Res Opin, 22:1927.

Ho YV, Frauman AG, Thomson W, et al. 2000. Effects of alendronate on bone density in men with primary and secondary osteoporosis. Osteoporos Int, 11:98-101.

Hodsman A, Papaioannou A, Ann C. 2006. Clinical practice guidelines for the use of parathyroid hormone in the treatment of osteoporosis. CMAJ, 175:48.

Jiang HX, Majumdar SR, Dick DA, et al. 2005. Development and initial validation of a risk score for predicting in-hospital and 1-year mortality in patients with hip fractures. J Bone Miner Res, 20:494-500. 
Jilka RL, Weinstein RS, Bellido T, et al. 1999. Increased bone formation by prevention of osteoblast apoptosis with parathyroid hormone. J Clin Invest, 104:439-46.

Johnell O, Kanis J, Gullberg G. 2001. Mortality, morbidity, and assessment of fracture risk in male osteoporosis. Calcif Tissue Int, 69:182-4.

Kaufman JM, Orwoll E, Goemaere S, et al. 2005. Teriparatide effects on vertebral fractures and bone mineral density in men with osteoporosis: treatment and discontinuation of therapy. Osteoporos Int, 16:510-6.

Khosla S, Amin S, Orwoll E. 2008. Osteoporosis in men. Endocr Rev, 29:441-64.

Khosla S, Melton LJ 3rd, Atkinson EJ, et al. 1998. Relationship of serum sex steroid levels and bone turnover markers with bone mineral density in men and women: a key role for bioavailable estrogen. JClin Endocrinol Metab, 83:2266-74.

Klotzbuecher CM, Ross PD, Landsman PB, et al. 2000. Patients with prior fractures have an increased risk of future fractures: a summary of the literature and statistical synthesis. J Bone Miner Res, 15:721-39.

Kukuljan S, Bass S, Salmon J, et al. 2006. Does calcium-vitamin D3 fortified milk enhance the effects of exercise on BMD in older men: An 18 month randomised controlled trial. J Bone Miner Res, 21:S184.

Kurland ES, Cosman F, McMahon DJ, et al. 2000. Parathyroid hormone as a therapy for idiopathic osteoporosis in men: effects on bone mineral density and bone markers. J Clin Endocrinol Metab, 85:3069-76.

Kurland ES, Heller SL, Diamond B, et al. 2004. The importance of bisphosphonate therapy in maintaining bone mass in men after therapy with teriparatide [human parathyroid hormone(1-34)]. Osteoporos Int, 15:992-7.

Lau E, Ong K, Kurtz S, et al. 2008. Mortality following the diagnosis of a vertebral compression fracture in the Medicare population. $J$ Bone Joint Surg Am, 90:1479-86.

Leder BZ, Leblanc KM, Schoenfeld DA, et al. 2003. Differential effects of androgens and estrogens on bone turnover in normal men. $J$ Clin Endocrinol Metab, 88:204-10.

Lenart BA, Lorich DG, Lane JM. 2008. Atypical fractures of the femoral diaphysis in postmenopausal women taking alendronate. $N$ Engl J Med, 358:1304-6.

Lips P. 2001. Vitamin D deficiency and secondary hyperparathyroidism in the elderly: consequences for bone loss and fractures and therapeutic implications. Endocr Rev, 22:477-501.

Lord SR, Castell S, Corcoran J, et al. 2003. The effect of group exercise on physical functioning and falls in frail older people living in retirement villages: a randomized, controlled trial. J Am Geriatr Soc, 51:1685-92.

Lyles KW, Colon-Emeric CS, Magaziner JS, et al. 2007. Zoledronic acid and clinical fractures and mortality after hip fracture. $N$ Engl J Med, 357:1799-809.

McCombs JS, Thiebaud P, McLaughlin-Miley C, et al. 2004. Compliance with drug therapies for the treatment and prevention of osteoporosis. Maturitas, 48:271-87.

Melton LJ 3rd, Atkinson EJ, Cooper C, et al. 1999. Vertebral fractures predict subsequent fractures. Osteoporos Int, 10:214-21.

Meryn S. 2005. Undertreatment of osteoporosis in men. Arch Intern Med, 165:241.

Meunier PJ, Boivin G. 1997. Bone mineral density reflects bone mass but also the degree of mineralization of bone: therapeutic implications. Bone, 21:373-7.

Michaelsson K, Olofsson H, Jensevik K, et al. 2007. Leisure physical activity and the risk of fracture in men. PLoS Med, 4:e199.

Miller PD, Bilezikian JP, Diaz-Curiel M, et al. 2007. Occurrence of hypercalciuria in patients with osteoporosis treated with teriparatide. J Clin Endocrinol Metab, 92:3535-41.

Miyakoshi N, Kasukawa Y, Linkhart TA, et al. 2001. Evidence that anabolic effects of PTH on bone require IGF-I in growing mice. Endocrinology, 142:4349-56.

National Cancer Institute Surveillance Research Program. SEER Stat software version 6.1.4. 2001. Osteoporosis prevention, diagnosis, and therapy. JAMA, 285:785-95.
Neer R, Hayes A, Rao A, et al. 2002. Effects of parathyroid hormone, alendronate, or both on bone density in osteoporotic post-menopausal women. J Bone Miner Res, 17:S135.

Neer RM, Arnaud CD, Zanchetta JR, et al. 2001. Effect of parathyroid hormone (1-34) on fractures and bone mineral density in postmenopausal women with osteoporosis. N Engl J Med, 344:1434-41.

Nevitt MC, Chen P, Kiel DP, et al. 2006. Reduction in the risk of developing back pain persists at least 30 months after discontinuation of teriparatide treatment: a meta-analysis. Osteoporos Int, 17:1630-7.

Nishida S, Yamaguchi A, Tanizawa T, et al. 1994. Increased bone formation by intermittent parathyroid hormone administration is due to the stimulation of proliferation and differentiation of osteoprogenitor cells in bone marrow. Bone, 15:717-23.

Oreffo RO, Mundy GR, Seyedin SM, et al. 1989. Activation of the bonederived latent TGF beta complex by isolated osteoclasts. Biochem Biophys Res Commun, 158:817-23.

Orwoll E, Ettinger M, Weiss S, et al. 2000. Alendronate for the treatment of osteoporosis in men. N Engl J Med, 343:604-10.

Orwoll ES, Klein R. 2001. Osteoporosis in men. Epidemiology, pathophysiology, and clinical characterization. In: Marcus, R., Feldman, D., Kelsey, J. (ed.) Osteoporosis. 2nd ed. San Diego: Academic Press.

Orwoll E, Lambert LC, Marshall LM, et al. 2006. Testosterone and estradiol among older men. J Clin Endocrinol Metab, 91:1336-44.

Orwoll ES, Scheele WH, Paul S, et al. 2003. The effect of teriparatide [human parathyroid hormone (1-34)] therapy on bone density in men with osteoporosis. J Bone Miner Res, 18:9-17.

Quattrocchi E, Kourlas H. 2004. Teriparatide: a review. Clin Ther, 26:841-54.

Reeve J, Meunier PJ, Parsons JA, et al. 1980. Anabolic effect of human parathyroid hormone fragment on trabecular bone in involutional osteoporosis: a multicentre trial. Br Med J, 280:1340-4.

Riggs BL, Melton LJ, Robb RA, et al. 2008. A population-based assessment of rates of bone loss at multiple skeletal sites: evidence for substantial trabecular bone loss in young adult women and men. $J$ Bone Miner Res, 23:205-14.

Ringe JD, Faber H, Farahmand P, et al. 2006. Efficacy of risedronate in men with primary and secondary osteoporosis: results of a 1-year study. Rheumatol Int, 26:427-31.

Scane AC, Francis RM, Sutcliffe AM, et al. 1999. Case-control study of the pathogenesis and sequelae of symptomatic vertebral fractures in men. Osteoporos Int, 9:91-7.

Seeman E. 2002. Pathogenesis of bone fragility in women and men. Lancet, 359:1841-50.

Silva MJ, Gibson LJ. 1997. Modeling the mechanical behavior of vertebral trabecular bone: effects of age-related changes in microstructure. Bone, 21:191-9.

Stroup J, Kane MP, Abu-Baker AM. 2008. Teriparatide in the treatment of osteoporosis. Am J Health Syst Pharm, 65:532-9.

Stroup J, Kane MP, Busch RS. 2003. Pharmacist-run teriparatide clinic. Am $J$ Health Syst Pharm, 60:2247-9.

Tam CS, Heersche JN, Murray TM, et al. 1982. Parathyroid hormone stimulates the bone apposition rate independently of its resorptive action: differential effects of intermittent and continuous administration. Endocrinology, 110:506-12.

Tang BM, Eslick GD, Nowson C, et al. 2007. Use of calcium or calcium in combination with vitamin $\mathrm{D}$ supplementation to prevent fractures and bone loss in people aged 50 years and older: a meta-analysis. Lancet, 370:657-66.

Tinetti ME. 2003. Clinical practice. Preventing falls in elderly persons. N Engl J Med, 348:42-9.

Vieth R, Chan PC, MacFarlane GD. 2001. Efficacy and safety of vitamin D3 intake exceeding the lowest observed adverse effect level. $\mathrm{Am}$ J Clin Nutr, 73:288-94.

Visekruna M, Wilson D, McKiernan FE. 2008. Severely suppressed bone turnover and atypical skeletal fragility. J Clin Endocrinol Metab, 93:2948-52. 
